\title{
As Principais Características do Patrimônio Turístico Italiano ReLacionadas À SUA Terminologia
}

\author{
RoSemary Irene CASTañeda ZanetTe
}

RESUMO: A Itália é o país que mais possui sítios da Lista do Patrimônio Mundial da UNESCO em seu território. São 878 sítios, distribuídos por 145 países. Tais exemplares são importantes não só para o país que os possui, mas para todo o mundo, pois são exemplos conservados de paisagens naturais ou de edificações de vários períodos da história. Além do ponto de vista da preservação, os 43 sítios que se encontram na Itália são atrativos turísticos, que movimentam o setor turístico, gerando divisas. Desta forma, a importância desta lista abrange a esfera cultural, no sentido de que o povo deve, além de apreciar, cuidar de seus bens, e a esfera do Turismo, uma das atividades econômicas que mais tem crescido nos últimos anos. Por fim, uma análise da terminologia empregada para denominar os sítios pode indicar alguns traços das paisagens culturais e naturais mais valorizadas neste território. PALAVRAS-CHAVE: patrimônio mundial; turismo; preservação; terminologia; UNESCO. 
ABSTRACT: L'Italia è il paese più ricco di siti archeologici della Lista del Patrimonio Mondiale dell'UNESCO. Sono in tutto 878 siti distribuiti in 145 paesi. Sono importanti non solo per il paese in cui si trovano, ma per il mondo intero, perché sono esempi preservati di paesaggi naturali o di edifici di vari periodi storici. Oltre al fattore preservazione, i 43 siti che si trovano in Italia sono attrattive turistiche che generano introiti. L'importanza di questa lista, quindi, coinvolge la sfera culturale, dato che la popolazione deve, non solo apprezzare i beni del suo territorio, ma anche tutelarli, e il settore turistico è una delle attività economiche che è cresciuta notevolmente negli ultimi anni. Una analise della terminologia usata per denominare i siti può, dunque, indicare alcuni aspetti dei paesaggi culturali e naturali più valorizzati in Italia.

PAROLE CHIAVE: patrimonio mondiale; turismo; preservazione; terminologia; UNESCO.

ABSTRACT: Italy is the country that has more sites on the List of World Heritage by UNESCO in its territory. They are 878 sites, spread over 145 countries. Its importance, not only for the country that has, but for the whole world, is due to the fact of being preserved examples of natural landscapes and buildings of various periods of history. Apart from the viewpoint of preservation, the 43 sites that are in Italy are tourist attractions, generating foreign currency for the country. Thus, the importance of this list covers the cultural sphere, in the sense that the people should enjoy besides, look after their property, and sphere of tourism, one of the economic activities that has grown in recent years. Finally, an analysis of the terminology used to name the sites may indicate some features of the natural and cultural landscapes more valued by this country.

KEYWORDS: World Heritage, Tourism, Preservation; Terminology; UNESCO. 


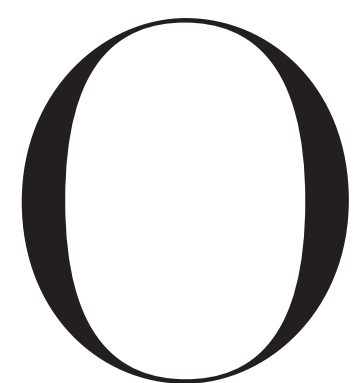

presente trabalho possui dois objetivos: apresentar a importância do Patrimônio Turístico Italiano para a Itália e para o mundo e analisar a terminologia usada para denominar os sítios da Lista do Patrimônio Mundial no território mencionado.

Inicialmente é preciso compreender alguns conceitos. O primeiro deles trata do que é entendido, na língua de especialidade do Turismo, por Patrimônio Turístico. Em primeiro lugar, ele é considerado, pela Organização Mundial do Turismo (OMT, 2003, p. 143), uma das vinte subáreas da grande área do Turismo. Um dicionário técnico elaborado em Portugal, um dos primeiros países a se preocupar com a terminologia desta área, define Patrimônio Turístico como "conjunto de obras e/ou monumentos de valor histórico, artístico, cultural, religioso, etc., de um país, região ou localidade” (DOMINGUES, 1990, p. 202). Nesta definição nota-se que é ressaltado o caráter cultural, já que a marca do homem sobre estes bens é evidente. Porém, não é feita nenhuma menção aos bens naturais, que também fazem parte do Patrimônio Turístico, como os de caráter biológico, paisagístico, geomorfológico. Pressupõe-se que tais bens não sofreram grandes transformações devido à presença ou passagem do homem por eles, mantendo, então, grande parte de suas características. Tendo em mente este conceito, agora complementado, é possível entender no que consiste a Lista do Patrimônio Mundial da Organização das Nações Unidas para a Educação, a Ciência e a Cultura (UNESCO).

A instituição merece algumas palavras. Trata-se de uma agência especializada das Nações Unidas, que atua nos setores da Educação, Ciências Naturais, Ciências Humanas 
e Sociais, Cultura, Comunicação e Informação. Em relação ao setor Cultura, entre tantas tarefas, a agência se ocupa do Patrimônio Turístico que possui importância em nível mundial. Foi em 1972 que elaborou a "Convenção sobre a Proteção do Patrimônio Mundial Cultural e Natural”, a qual deve ser seguida por todos os Estados-membros. Dentre seus objetivos estão a identificação, a preservação e a proteção dos bens. Assim, este é o primeiro instrumento normativo que regulamenta as atividades em relação ao assunto, fornecendo as linhas mestras que devem ser seguidas, partindo dos conceitos fundamentais, como os de Patrimônio Cultural e Patrimônio Natural, além de estabelecer os critérios para identificá-los (seis para o primeiro e dez para o segundo) e, principalmente, apresentando a primeira Lista do Patrimônio Mundial com sítios de todas as partes do mundo. Julga-se importante apresentar os conceitos contidos no documento. São eles:

Patrimônio Cultural é composto por monumentos, grupos de edifícios ou sítios que tenham valor histórico, estético, arqueológico, científico, etnológico ou antropológico.

Patrimônio Natural significa as formações físicas, biológicas e geológicas excepcionais, habitats de espécies animais e vegetais ameaçadas e áreas que tenham valor científico, de conservação ou estético.

Tais conceitos são seguidos até hoje. Em relação à atual Lista do Patrimônio Mundial, o site da instituição em língua inglesa informa que hoje são 878 bens, divididos entre 679 culturais, 174 naturais e 25 mistos, ou seja, com características dos outros dois, distribuídos por 145 Estados-membros. Até 2007, a Itália possuía 41 sítios em seu território, sendo 40 deles considerados culturais e apenas um natural, isto é, as Ilhas Eólicas, na Sicília. Com a $32^{a}$ reunião do Comitê do Patrimônio Mundial da UNESCO, em julho de 2008, foram incluídos na lista mais 27 bens, sendo dois italianos: "Mantova e Sabbioneta" e "La ferrovia retica nel paesaggio dell’Albula e del Bernina", com a primeira parte na Suíça e a segunda na Itália. ${ }^{\circledR}$ Este país, com 43 sítios da Lista do Patrimônio Mundial em seu território, continua ocupando o primeiro lugar no quesito quantidade de sítios. Esta contagem se refere ao Patrimônio Cultural e ao Natural. Porém, com o passar do tempo, a instituição percebeu que o documento de 1972 não estava abarcando mais todas as particularidades do Patrimônio. Então, em 2003, foi finalizada e adotada a "Convenção para a Salvaguarda do Patrimônio Cultural Imaterial”, apresentando a nova categoria, Patrimônio Imaterial, como subdivisão do Patrimônio Cultural.

Entende-se por “patrimônio cultural imaterial” as práticas, representações, expressões, conhecimentos e técnicas - junto com os instrumen- 
tos, objetos, artefatos e lugares culturais que lhes são associados - que as comunidades, os grupos e, em alguns casos, os indivíduos reconhecem como parte integrante de seu patrimônio cultural.

O conceito de Patrimônio Cultural data de 1972. Em 2003 foi instituída a ramificação Patrimônio Cultural Imaterial, definida pela nova convenção, e, consequentemente, o que até então era entendido como Patrimônio Cultural torna-se Patrimônio Cultural Material. Para ter clareza do conceito deste último, é preciso analisar a nova convenção, além dos critérios de identificação dos sítios de natureza cultural, estabelecidos pela primeira. São eles:

i. representar uma obra-prima do gênio criativo humano, ou

ii. ser a manifestação de um intercâmbio considerável de valores humanos durante um determinado período ou em uma área cultural específica, no desenvolvimento da arquitetura, das artes monumentais, de planejamento urbano ou de paisagismo, ou

iii. aportar um testemunho único ou excepcional de uma tradição cultural ou de uma civilização ainda viva ou que tenha desaparecido, ou

iv. ser um exemplo excepcional de um tipo de edifício ou de conjunto arquitetônico ou tecnológico, ou de paisagem que ilustre uma ou várias etapas significativas da história da humanidade, ou

v. constituir um exemplo excepcional de habitat ou estabelecimento humano tradicional ou do uso da terra, que seja representativo de uma cultura ou de culturas, especialmente as que se tenham tornado vulneráveis por efeitos de mudanças irreversíveis, ou

vi. estar associados diretamente ou tangivelmente a acontecimentos ou tradições vivas, com idéias ou crenças, ou com obras artísticas ou literárias de significado universal excepcional (O Comitê considera que este critério não deve justificar a inscrição na Lista, salvo em circunstâncias excepcionais e na aplicação conjunta com outros critérios culturais ou naturais).

É igualmente importante o critério da autenticidade do sítio e a forma pela qual esteja protegido e administrado.

Tendo em vista o conceito apresentado, por exclusão, o Patrimônio Cultural Material não pode ser, de modo geral, objeto ou prática de determinados grupos. Em relação aos critérios, é importante ressaltar que nenhum bem é selecionado por apenas um cri- 
tério, devendo ser atendido sempre mais de um. Observando-os, então, pode-se afirmar que o primeiro e o sexto não trazem contribuições neste caso. O critério $i$ poderia também ser aplicado ao Patrimônio Cultural Imaterial, pois não traz nenhuma especificidade. Quanto ao critério vi, ele traz uma palavra-chave, "tangivelmente". Em seu sentido mais imediato, ela significa o que é palpável. Pode-se concluir, então, que o Patrimônio Material seria o palpável e o Patrimônio Imaterial, seu contrário, ou seja, o impalpável. Esta é uma idéia muito simplista, que acaba funcionando no caso dos bens italianos, ou seja, "Teatro delle Marionette Siciliane: Opera dei Pupi" e "Canto a Tenore dei Pastori del centro della Barbagia”. ${ }^{\circledR} \mathrm{O}$ primeiro trata da manifestação artística que é o teatro, com uso de objetos significativos para ele, as marionetes; o segundo diz respeito também a uma manifestação artística, o canto, desta vez, porém, sem elementos materiais. Em ambos os casos, a arte, como um todo, é impalpável. O que poderia, então, auxiliar neste entendimento é dizer que o Patrimônio Material dificilmente pode ser transferido no território, sendo em muitos casos, impossível de ser feito, como no caso dos "Trulli di Alberobello" (construções pré-históricas da cidade), ou então em relação à "Venezia e la sua Laguna". Já o Patrimônio Imaterial, apesar de originário e característico de certa região, pode ser transportado. Por fim, pode-se dizer que os termos em italiano, "Patrimonio Orale e Immateriale dell'Umanità" (Patrimônio Oral e Imaterial da Humanidade) e, em inglês, "Intangible Heritage" (Patrimônio Intangível) são mais adequados.

Compreendidos os conceitos, este trabalho deu indícios de que o Patrimônio Turístico envolve duas importantes esferas, as quais possuem objetivos muito diferentes. São elas, o Turismo e a Cultura, mais especificamente o setor da Preservação.

Em relação ao Turismo, pode-se afirmar que essa atividade econômica está entre as que mais se desenvolvem mundialmente e geram divisas. A pesquisa da OMT, publicada em junho deste ano, indica que houve um crescimento de $5 \%$ nos primeiros quatro meses do ano, em relação ao mesmo período de 2007. Outro dado é que, entre os dez países que mais recebem turistas por ano, China e Itália têm-se alternando na quarta e quinta colocações. ${ }^{\Downarrow}$ Além deste estudo, todos os anos o World Economic Forum (WEF) publica a "Travel \& Tourism competitiviness report”'. A publicação de 2008, com os dados de 2007, envolveu 130 países. Entre os aspectos tratados estão itens básicos do setor turístico como sua regulamentação, higiene e segurança. É verificada também a questão da infraestrutura e, por fim, questões relativas aos recursos humanos (educação e treinamento, qualificação do trabalho). Outro item avaliado é a presença dos bens naturais e culturais nestes territórios. Um dos resultados, analisados todos os quesitos, mostra que a Itália é o $28^{\circ}$ país quanto à competitividade turística. Os pontos fortes do país são representados por sua primeira colocação em relação à quantidade de sítios do Patrimônio Cultural da Lista da UNESCO, o que já foi comentado, e quarta em relação à infraestrutura dos serviços que oferece. 
Verificada a importância do Turismo para o país, resta tratar da preservação do Patrimônio, sob responsabilidade da UNESCO, em nível mundial, mas internamente gerida pelo Ministero per i Beni e le Attività Culturali (MiBAC). Além de a Itália possuir um ministério inteiro para tratar de questões culturais, pode-se afirmar que, neste sentido, ele desempenha muito bem suas funções, principalmente quanto à regulamentação, pois suas leis contemplam tanto os bens culturais quanto os naturais. Um dos principais documentos norteadores, entre uma série de documentações, é o "Codice dei Beni Culturali

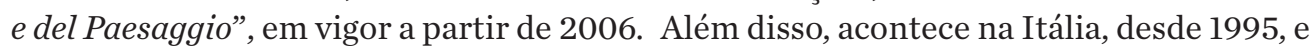
em toda a Europa, desde 1999, o evento conhecido como "Giornate Europee del Patrimonio", em que muitos monumentos e sítios, geralmente fechados ao público, são abertos à visitação gratuita. Os locais são de tipologia cultural, como castelos, museus, galerias, e de tipologia natural, como parques, grutas e cascatas. ${ }^{\rrbracket}$ Atualmente são 49 os países participantes. Na Itália, as jornadas acontecem no mês de setembro. Em 2008 as datas escolhidas foram 27 e 28 de setembro. O tema italiano foi "Le Grandi Strade della Cultura. Viaggio tra i Tesori d'Italia”. Segundo a própria organização,

[...] le Giornate Europee del Patrimonio sono diventate uno strumento fondamentale per lo sviluppo di una esperienza tangibile della cultura e della storia europea e per la crescita della coscienza del pubblico circa $i$ molteplici valori del nostro patrimonio comune e del continuo bisogno di salvaguardarlo.

Nota-se que a idéia não é exclusivamente italiana, mas adotada em todo o continente europeu, e, portanto, reflete a importância que é dada por esse países à cultura, ao conhecimento e, consequentemente, à valorização dos seus bens.

Vista a forma como a Itália vê e trata o seu Patrimônio Turístico, pode-se prosseguir com o trabalho, analisando a terminologia em língua italiana utilizada para denominar os sítios incluídos na Lista do Patrimônio Mundial que estão em seu território.

Em primeiro lugar, ressalta-se a dificuldade encontrada ao deparar-se com diversos termos para designar um mesmo tipo de sítio. Selecionou-se a lista que se encontra no site do MiBAC, na seção dedicada à UNESCO, para dela se extrair a denominação dos sítios. Ao lado de cada uma, segue a respectiva data de inscrição na lista.

1) Arte rupestre della Valcamonica (1979)

2) Centro storico di Roma, le proprietà extraterritoriali della Santa Sede nella città e San Paolo fuori le Mura (1980 e 1990)

3) La chiesa ed il convento domenicano di Santa Maria delle Grazie con "La cena” di Leonardo Da Vinci (1980) 
4) Centro storico di Firenze (1982)

5) Venezia e la sua Laguna (1987)

6) La piazza del Duomo di Pisa (1987)

7) Centro storico di San Gimignano (1990)

8) I Sassi e il parco delle Chiese rupestri di Matera (1993)

9) Vicenza e le Ville del Palladio nel Veneto (1994 e 1996)

10) Centro storico di Siena (1995)

11) Centro storico di Napoli (1995)

12) Crespi d’Adda (1995)

13) Ferrara città del Rinascimento e il suo delta del Po (1995 e 1999)

14) Castel del Monte (1996)

15) I trulli di Alberobello (1996)

16) Monumenti paleocristiani di Ravenna (1996)

17) Centro storico della città di Pienza (1996)

18) Aree archeologiche di Pompei, Ercolano e Torre Annunziata (1997)

19) Il Palazzo Reale del XVIII secolo di Caserta con il Parco, l'Acquedotto vanvitel liano ed il Complesso di San Leucio (1997)

20) Costiera Amalfitana (1997)

21) Modena: Cattedrale, Torre Civica e Piazza Grande (1997)

22) Portovenere, Cinque Terre e Isole Palmaria, Tino e Tinetto (1997)

23) Residenze Sabaude (1997)

24) Su Nuraxi di Barumini (1997)

25) Area archeologica di Agrigento (1997)

26) Piazza Armerina, villa romana del Casale (1997)

27) Orto Botanico di Padova (1997)

28) Area archeologica di Aquileia e basilica Patriarcale (1998)

29) Centro storico di Urbino (1998)

30) Parco Nazionale del Cilento e del Vallo di Diano con i siti archeologici di Paestum e Velia e la Certosa di Padula (1998)

31) Tivoli, Villa Adriana (1999)

32) Isole Eolie (2000)

33) Verona (2000)

34) Assisi, la Basilica di San Francesco e altri siti francescani (2000)

35) Tivoli, Villa d'Este (2001)

36) Le città barocche della Val di Noto (2002)

37) Sacri Monti di Piemonte e Lombardia (2003)

38) Val d'Orcia (2004) 
39) Le necropoli etrusche di Cerveteri e Tarquinia (2004)

40) Siracusa e le necropoli rupestri di Pantalica (2005)

41) Genova: Le Strade Nuove ed il sistema dei Palazzi dei Rolli (2006)

42) Mantova e Sabbioneta (2008)

43) La ferrovia retica nel paesaggio dell’Albula e del Bernina (2008)』 ${ }^{\circledR}$

Observando-se a terminologia empregada, destacam-se alguns aspectos importantes. O primeiro deles se refere à complexidade dos termos, consequência da complexidade do sítio, devido seja à sua extensão seja ao que agrupa. Muitos sitos compreendem mais de um bem, mas, por estes estarem próximos no território e por possuírem algumas características semelhantes, são agrupados em uma única denominação. Isso ocorre em 14 casos, entre os quais estão "I Sassi e il parco delle Chiese rupestri di Matera" (dois bens); "Vicenza e le Ville del Palladio nel Veneto" (dois bens); "Ferrara città del Rinascimento e il suo delta del Po" (dois bens). A indicação de mais de um bem pode ser observada no termo pela conjunção "e", que liga um bem/conjunto e outro bem/conjunto, mas isso nem sempre funciona. É o caso de "Venezia e la sua Laguna" que indica apenas um sítio. Não é possível, portanto, chegar a conclusões apenas observando o termo, sendo preciso compreender melhor as características do sítio e os critérios utilizados para classificá-lo.

A extensão do sítio também é importante. Em muitos dos casos, um sítio ocupa parte significativa de uma cidade. Esta realidade é expressa por termos como "Centro Storico", "strutture insediative urbane che costituiscono unità culturale o la parte originaria e autentica di insediamenti ${ }^{\Downarrow ”}$. São sete os casos como, por exemplo, "Centro Storico di Firenze", "Centro Storico di Urbino". Situação semelhante é expressa pelo termo "area archeologica", como no caso específico de "Aree archeologiche di Pompei, Ercolano e Torre Annunziata", "Area archeologica di Agrigento" e "Area archeologica di Aquileia e Basilica patriarcale", além dos sítios desta natureza encontrados no "Parco Nazionale del Cilento e del Vallo del Diano con i siti arqueologici di Paestum e Velia e la Certosa di Padula". Há também termos que representam sítios distribuídos por mais de uma cidade ou região, como no caso de "Aree archeologiche di Pompei, Ercolano e Torre Annunziata” (sítios arqueológicos em três cidades da região Campania); "Le città barocche della Val di Noto" (que compreende as cidades de Palazzolo Acreide, Caltagirone, Catania, Militello in Val di Catania, Modica, Noto, Ragusa e Scicli); "Sacri Monti di Piemonte e Lombardia" (montes em duas regiões do norte do país) e "Le necropoli etrusche di Cerveteri e Tarquinia” (necrópoles em duas cidades da região Lazio). ${ }^{\otimes}$ Por fim, acontece também do termo continuar complexo, mas a extensão do território que ele representa ser menor, pois são selecionados os bens mais significativos daquele es- 
paço. É o caso de “Modena: Cattedrale, Torre Civica e Piazza Grande”, “Assisi: la Basilica di San Francesco e altri siti francescani”.

Outro aspecto marcante da lista é a presença de um topônimo em 41 das 43 denominações. Este procedimento torna o bem único, já que, fazendo parte de uma lista mundial, associá-los a um nome de lugar facilita sua identificação. Isso funciona muito bem com relação a áreas arqueológicas, centros históricos, os quais possuem muitos exemplares, na Itália ou em outros países do mundo. Tratando-se mais especificamente das denominações em italiano, há cinco casos em que o topônimo representa integralmente o sítio, como em "Costiera Amalfitana", "Isole Eolie", "Verona", "Val d’Orcia" e, por fim, "Mantova e Sabbioneta" (cidades consideradas um único sítio por possuírem características semelhantes). Há dois casos em que o uso do topônimo é utilizado com caráter enfático, já que os bens existem apenas em território italiano e a função de localização desaparece. Os exemplos são "I Trulli di Alberobello" e "Su Nuraxi di Barumini”. Quanto ao primeiro caso, as construções pré-históricas conhecidas como "trullo" existem também em outras cidades da região Puglia, mas é em Alberobello que elas estão mais bem conservadas. O mesmo acontece com os "nuraghi", bens de natureza semelhante, não idêntica, da cidade de Barumini, região Sardegna. Nos demais 34 casos, o topônimo representa apenas parte do sítio. Os dois casos restantes são compostos apenas pelos bens, como em "La chiesa e il convento di Santa Maria delle Grazie con 'La cena' di Leonardo da Vinci" e "Residenze Sabaude", em que o segundo termo é o adjetivo relativo à família Savoia, importante na história do país.

Outra questão observada é que, segundo os critérios da UNESCO, 42 sítios dos 43 mencionados são culturais e apenas um, "Isole Eolie", é natural. Porém, muitos dos sítios estão localizados em paisagens naturais ou associados a algum bem natural, os quais foram importantes para sua inclusão na Lista do Patrimônio Mundial. Além do exemplo apenas citado, existem outros oito. São eles: "Arte rupestre della Valcamonica" (devido ao vale em que se encontra); "Venezia e la sua Laguna" (devido à presença da lagoa, por toda a cidade); "Il Palazzo Reale del XVIII secolo di Caserta con il Parco, l’Acquedotto vanvitelliano ed il Complesso di San Leucio" (pela presença do parque); "Costiera Amalfitana" (devido à paisagem natural); "Orto Botanico di Padova" (devido ao seu jardim); "Parco Nazionale del Cilento e del Vallo di Diano con i siti archeologici di Paestum e Velia e la Certosa di Padula" (a categoria "parque nacional", num primeiro momento, refere-se a características naturais; é considerada cultural quando há indícios da presença humana em períodos históricos mais remotos); "Sacri Monti di Piemonte e Lombardia" (devido à sua localização nos montes das duas regiões italianas); "La ferrovia retica nel paesaggio dell'Albula e del Bernina" (pela construção da ferrovia ter sido feita em meio a uma paisagem natural, parte na Suíça e parte na Itália). 
Ao olhar o conjunto dos termos da lista italiana, percebe-se a grande ocorrência de alguns termos, que representam uma tipologia de sítios recorrente, ao passo que há também outros termos que representam sítios particulares. No primeiro caso, estão os sítios arqueológicos, três propriamente ditos e mais um que possui apenas uma parte deste tipo de bem, como o "Parco Nazionale del Cilento e del Vallo di Diano con $i$ siti archeologici di Paestum e Velia e la Certosa di Padula". Os sete centros históricos já foram mencionados. Foram encontradas quatro vilas: "Vicenza e le Ville del Palladio nel Veneto", "Piazza Armerina: Villa Romana del Casale", nestes casos, apenas parte do sítio, e ainda "Tivoli, Villa d'Este" e "Tivoli, Villa Adriana", que constituem o próprio sito. Há dois vales: "Arte rupestre della Valcamonica" e "Parco Nazionale del Cilento e del Vallo di Diano con i siti archeologici di Paestum e Velia e la Certosa di Padula”. Também há duas necrópoles, uma rupestre e uma etrusca. No segundo caso, em relação a sítios com traços especiais, está “La ferrovia retica nel paesaggio dell'Albula e del Bernina”. É a terceira ferrovia no mundo que faz parte da lista da UNESCO. Em meio a paisagens naturais, áreas arqueológicas e tantas edificações de diversos períodos da história, a construção deste sistema de transporte, além de diferir da natureza dos outros bens, é o mais "novo" da lista italiana. A "Ferrovia Bernina", parte italiana, funciona desde 1908, mas só 34 anos depois é que começou a integrar uma ferrovia maior, com extensão na Suíça.

Após compreender os principais aspectos expressos pelos termos que denominam os sítios da lista italiana do Patrimônio Mundial, prossegue-se com observações de caráter mais estrutural. Percebe-se a ausência de homogeneidade na denominação, já que um bem, muitas vezes denominado e relacionado a uma cidade ou região onde se encontra, é representado de três formas diferentes. Numa delas é representado pelo seu nome ligado ao nome do topônimo, como no caso de "Centro Storico di Firenze", "Area archeologica di Agrigento". Outras vezes é representado pelo nome do topônimo, seguido de vírgula, e então o nome do bem: "Tivoli, Villa d'Este"; "Piazza Armerina, Villa Romana del Casale". Há outra variação em que o topônimo é seguido de dois pontos: "Modena: Cattedrale, Torre Civica, e Piazza Grande"; "Genova: Le Strade Nuove e il Sistema dei Palazzi dei Rolli”. No caso dos centros históricos, dos sete existentes, um não segue a terminologia adotada nos outros casos, que era composta por "Centro Histórico", seguida do nome da cidade: "Centro Storico di Siena”. Neste caso excepcional, há elementos excedentes e desnecessários, representados por "della città di. Seria suficiente usar "Centro Storico di Pienza”, ao invés da forma atual "Centro Storico della città di Pienza".

A análise terminológica apenas apresentada reforça a idéia de que a Itália é um país que se preocupa com a preservação de seus bens, compreendendo exemplares dos mais variados períodos de sua história, importantes para o próprio país e importantes para o mundo. Entre esta grande diversidade estão alguns sítios arqueológicos, de períodos 
muito remotos, como no caso da "Area archeologica di Agrigento", exemplo de colônia grega do século VI a.C. Como exemplo de um período um pouco mais recente está a arte medieval que embelezou as edificações da cidade de Assis, entre outros. A inclusão feita recentemente na lista da "Ferrovia Bernina", símbolo de progresso, demonstra um novo olhar para os sítios italianos selecionados para a preservação. Começa-se a se desenhar um novo perfil dos futuros integrantes desta lista, com traços de certa modernidade. A idéia da preservação permanece, abrangendo, porém, uma nova diversidade de sítios, consequência da própria evolução dos povos. 


\section{Referências bibliográficas}

ASSOCIAZIONE CITTÀ E SITI ITALIANI PATRIMONIO MONDIALE UNESCO. Città e siti italiani. Disponível em: <http://www.sitiunesco.it/index.phtml?id=4>. Acesso em: 27 set. 2008.

ALVES, Ieda Maria. A delimitação da unidade lexical nas línguas de especialidade. In: BASÍLIO, Margarida. (Org.). A delimitação de unidades lexicais. Rio de Janeiro: Grypho, 1999.

BARROS, Lídia Almeida. Curso básico de terminologia. São Paulo: EDUSP: 2004.

BENI, Mário Carlos. Análise estrutural do turismo. 3. ed. rev. e ampl. São Paulo: Editora SENAC São Paulo, 2000.

DICIONÁRIO ELETRÔNICO HOUAISS DA LÍNGUA PORTUGUESA. Versão 1.0. Editora Objetiva, 2001. 1 CD-ROM.

DOMINGUES, Celestino de Matos Domingues. Dicionário técnico de turismo. Lisboa: Publicações Dom Quixote, 1990. p. 202.

MINISTERO PER I BENI E LE ATTIVITÀ CULTURALI. La lista. Ufficio Patrimonio Mondiale UNESCO. Disponível em: <http://www.unesco.beniculturali.it/index.php?it/40/la-lista >. Acesso em: 25 set. 2008.

Giornate europee del Patrimonio 2007. Disponível em: <http://www.beniculturali.it/giornate_ europee_08/cosa/index.html>. Acesso em: 26 set. 2008.

Giornate europee del Patrimonio 2008. Disponível em: <http://www.beniculturali.it/giornate_ europee_08/cosa/gep_italia.html>. Acesso em: 26 set. 2008.

. MiBAC. Normativa. Disponível em: <http://www.beniculturali.it/normativa/default.asp>. Acesso em: 26 set. 2008.

ORGANIZAÇÃO MUNDIAL DO TURISMO. Sinais e símbolos turísticos: guia ilustrado e descritivo. Traduçãoe Gabriela Scuta Gagliari. São Paulo: 2003. p. 143.

UNESCO. Convenção para a salvaguarda do Patrimônio Cultural Imaterial. Disponível em: <http://unesdoc. unesco.org/images/0013/001325/132540POR.pdf >. Acesso em: 24 set. 2008.

. A Convenção para a proteção do Patrimônio Mundial, Cultural e Natural. Disponível em: http://www. brasilia.unesco.org/areas/cultura/areastematicas/patrimoniomundial/copy2_of_index_html. Acesso em: 24 set. 2008.

Patrimônio Mundial. UNESCO - Brasil. Disponível em: http://www.brasilia.unesco.org/areas/cultura/ areastematicas/patrimoniomundial/patrimoniomundial. Acesso em: 23 set. 2008.

. World Heritage Centre. World Heritage List. Disponível em: <http://whc.unesco.org/en/list>. Acesso em: 23 set. 2008 .

UNWTO. UNWTO World Tourism Barometer. Vol. 6, $\mathrm{n}^{\mathrm{o}}$ 2, june 2008. Disponível em: <http://unwto.org/facts/ eng/pdf/barometer/UNWTO_Barom08_2_en_Excerpt.pdf.> Acesso em: 25 set. 2008.

WORLD ECONOMIC FORUM. The Travel \& Tourism Competitiveness Report 2008. Disponível em: <http:// www.weforum.org/ttcro8browse/index.html>. Acesso em: 25 set. 2008. 